\title{
Purge material berbasis campuran recycled HDPE dan lempung kaolin untuk ekstrusi polipropilena dan masterbatch
}

\section{Purge material based mixture of recycled HDPE and kaolin clay for polypropylene and masterbatch extrusion}

\author{
Fitria Ika Aryanti*, Elga Chaerul Pasya \\ Politeknik STMI Jakarta, Jalan Letjen Suprapto No. 26, Jakarta 10510, Indonesia \\ * Penulis korespondensi. Telp. (021) 42886064; Faks: (021) 42888206 \\ E-mail: fitria.ika@kemenperin.go.id
}

Diterima: 20 Nopember 2020

Direvisi: 22 Maret 2021

Disetujui: 6 April 2021

\begin{abstract}
Extruder (screw/barel system) has become very important equipment in the processing of plastic final products. The process of cleaning residues in extruder barel by inserting the purge material without diassembling the machine is called a purging extruder. This study aimed to determine the effect of kaolin clay at variations of 0, 3, 6, and 9\% in purge material of recycled High Density Polyethylene (HDPE) on the color and fuctional groups of extrudate. The colour measurement resulted that along with the addition of kaolin clay, the extrudate colour was getting cleaner from primer colour of PP/masterbatch. The optimum amount of added kaolin clay was $6 \%$ with a lower masterbatch content than other variations due to color contamination and low residual functional group content in extrudate.
\end{abstract}

Keywords: kaolin clay, masterbatch, polypropylene, purge material, recycled HDPE.

\begin{abstract}
ABSTRAK
Extruder (sistem screw/barel) telah menjadi alat yang sangat penting dalam pengolahan produk akhir plastik. Proses pembersihan residu dalam barel extruder dengan memasukkan bahan pembersih (purge material) tanpa membongkar mesin disebut purging extruder. Penelitian ini bertujuan untuk mengetahui pengaruh lempung kaolin pada variasi $0,3,6$, dan 9\% dalam bahan pembersih recycled high density polyethylene (HDPE) terhadap warna dan gugus fungsi ekstrudat. Hasil uji warna menunjukkan bahwa seiring penambahan lempung kaolin, warna ekstrudat bahan pembersih semakin bersih dari kontaminasi warna primer PP/masterbatch. Jumlah optimum penambahan lempung kaolin adalah 6\% dengan kandungan masterbatch lebih rendah dibandingkan variasi lainnya karena diperoleh kontaminasi warna dan kandungan gugus fungsi residu yang rendah pada ekstrudatnya.
\end{abstract}

Kata kunci: bahan pembersih, lempung kaolin, masterbatch, polipropilena, recycled HDPE.

\section{PENDAHULUAN}

Plastik dan proses pengolahannya telah menjadi salah satu bidang penting dalam kehidupan manusia di masa kini karena menjadi segala komponen pada sektor-sektor industri. Produk akhir plastik banyak diolah melalui proses ekstrusi (sistem screw/barel). Prinsip ekstrusi telah ditemukan sangat lama, dimulai dengan Archimedes screw yang digunakan pada industri makanan dan mulai digunakan untuk memproses polimer pada tahun 1870 (Agassant et al., 2017). Proses ekstrusi menghasilkan berbagai produk plastik, seperti pipa, kabel, berbagai macam profil, komponen-komponen otomotif, dan berbagai alat rumah tangga.

Alat ekstrusi, yaitu extruder yang telah digunakan untuk memproses plastik akan meninggalkan akumulasi bahan yang digunakan di dalam barel. Ketika alat extruder tersebut akan digunakan kembali maka akumulasi yang 
tertinggal dalam barel perlu dibersihkan terlebih dahulu. Hal tersebut bertujuan agar produk yang dihasilkan setelahnya tidak terkontaminasi bahan yang digunakan sebelumnya. Polimer yang banyak diproduksi menggunakan extruder adalah jenis polipropilena (PP). Bahan ini digunakan untuk berbagai keperluan rumah tangga, seperti botol minum, tempat makan, dan juga untuk komponen otomotif seperti karpet interior, bumper, dan lainnya. Produsen produk plastik menambahkan masterbatch sebagai biang pewarna dan zat aditif untuk mendapatkan produk yang diinginkan. Zat pewarna pada poliolefin dapat berupa pigmen dari senyawa organik, sedangkan aditif yang banyak ditambahkan untuk poliolefin adalah antioksidan (AO) dan ultraviolet (UV) stabilizer (Tolinski, 2015).

Resin yang banyak digunakan untuk membersihkan (purging) sisa polipropilena dalam barel tersebut adalah jenis High Density Polyethylene (HDPE). Untuk mempercepat proses purging, telah banyak perusahaan yang memproduksi kompon pembersih (purge compound), seperti merk dagang Dyna-Purge ${ }^{\circledR}$, Pax Purge ${ }^{\circledR}$, dan UniPurge ${ }^{\circledR}$. Kompon pembersih tersebut berbasis matriks resin HDPE. Perusahaan yang tidak menggunakan kompon pembersih menggunakan resin murni sebagai bahan pembersih (purge material) extruder. Material yang kekakuannya kurang seperti PP dapat menggunakan mechanical purge, jenis yang biasa digunakan adalah HDPE yang memiliki kekakuan dan viskositas lelehan lebih besar, sedangkan material yang memiliki kekakuan lebih tinggi digunakan jenis bahan pembersih yang lebih abrasif (Giles et al., 2004). Pencampuran PP dan HDPE menggunakan extruder menghasilkan polipaduan yang tidak membentuk ikatan kimia, sehingga HDPE dapat mendorong PP sepenuhnya keluar barel extruder tanpa bercampur (Lin et al., 2015). Recycled HDPE ini umum dimanfaatkan sebagai campuran pada pemrosesan polimer menggunakan virgin HDPE. Namun, penggunaan recycled HDPE tersebut dalam jumlah kecil karena akan mempengaruhi sifat mekanis dan termal produk yang dihasilkan. Oleh sebab itu, pemanfaatan recycled HDPE sebagai bahan pembersih diharapkan dapat mengurangi produk samping yang dihasilkan dan mengurangi biaya produksi.

Penambahan clay (lempung) pada HDPE membuat laju material melalui die menjadi lebih mudah dan bertindak sebagai pelumas (lubricant). Sebagian lempung yang bertindak sebagai pelumas mereduksi friksi antar rantai polimer sehingga viskositas lelehan polimer menurun (Gill et al., 2015). Hal tersebut membuat lelehan HDPE dan lempung dapat meraih sudut-sudut dalam barel untuk membersihkan sisa-sisa produk yang ingin dibersihkan. Pada penelitian Chukwubuike (2015), penggunaan campuran recycled HDPE, $\mathrm{SiO}_{2}$, dan lempung sebagai pembersih extruder menunjukkan bahwa komposisi recycled lempung $8,7 \%$ (120 gram) menghasilkan ekstrudat yang paling baik, sedangkan penggunaan $\mathrm{SiO}_{2}$ tidak berdampak signifikan. Pada penelitian tersebut, lempung yang ditambahkan sejumlah 80, 100, 120, 160 , dan 180 gram. Jenis lempung yang digunakan pada penelitian tersebut adalah lempung hijau yang memiliki bentuk illite (Chukwubuike, 2015).

Kaolin dengan berat jenis $2,6 \mathrm{~g} / \mathrm{cm}^{3}$ merupakan bahan pengisi paling ringan jika dibandingkan talc, kalsium karbonat, barite, dan kalsium inosilikat (Pukánszky, 2001). Lempung kaolin juga bersifat sebagai zat inert, sehingga dapat ditambahkan pada bahan pembersih tanpa menghasilkan reaksi terhadap residu yang ingin dibersihkan (Bajpai, 2016). Selain itu, lempung kaolin merupakan mineral yang rendah tingkat abrasifnya sehingga tidak mengikis screw (Lewis, 2007). Recycled HDPE banyak digunakan sebagai material yang dapat digunakan kembali sebagai bahan baku produk, namun jika penggunaannya dilakukan berkali-kali akan mengurangi sifat mekanis maupun termal material tersebut, sehingga dilakukan alternatif pemanfaatan recycled HDPE sebagai kompon pembersih proses ekstrusi. Di lain hal, lempung kaolin yang memiliki struktur kaolite selain dapat dimanfaatkan sebagai filler komposit juga sebagai tambahan material kompon pembersih.

Berdasarkan hal di atas, penggunaan lempung kaolin belum pernah digunakan sebagai bahan pembersih, maka diperlukan penelitian mengenai hal tersebut. Penelitian ini menggunakan recycled HDPE dan lempung kaolin sebagai bahan pembersih untuk ekstrusi polipropilena dan masterbatch. Penelitian ini menggunakan analisis perubahan warna secara spektroskopi sehingga diperoleh data yang lebih akurat dibanding penelitian sebelumnya yang hanya menggunakan kasat mata. Tujuan penelitian ini adalah mengetahui pengaruh lempung kaolin pada variasi $0,3,6$, dan $9 \%$ dalam bahan pembersih 
recycled HDPE terhadap warna dan gugus fungsi ekstrudat. Kondisi optimum yang diinginkan yaitu variasi dengan kontaminasi warna dan gugus fungsi residu yang rendah pada ekstrudatnya.

\section{BAHAN DAN METODE Bahan Penelitian}

Penelitian inimenggunakan resin polipropilena (TRILENE® HI10HO) dan masterbatch merah dengan carrier resin Low Density Polyethylene (HAIMASTER $®$ Red $418 C$ ) sebagai campuran awal untuk dibersihkan. Resin recycled HDPE (Langgeng Jaya, HD-AXI L2020/PC14) sebagai basis bahan pembersih (PM), dan lempung kaolin $\mathrm{Al}_{2} \mathrm{Si}_{2} \mathrm{O}_{5}(\mathrm{OH})_{4}$ (Aneka Kaolin Utama, White Kaolin Powder-325) sebagai bahan tambahan yang mempermudah proses pembersihan (purging).

\section{Peralatan Penelitian}

Peralatan proses ekstrusi yang digunakan adalah extruder twin screw merek Collin $\mathbb{R}$ tipe TEACH-Line Compounder ZK $25 \times 24 D$, dilengkapi waterbath dan pelletizer. Alat untuk menganalisis hasil purging adalah attenuated total reflectance-fourier transform infrared (ATRFTIR) spectroscopy merek Thermo Scientific Nicolet tipe iS20, serta untuk analisis warna adalah colorimetric spectrometer merek Konica Minolta tipe DM-3600D. Proses pembuatan pelat spesimen menggunakan alat manual forming machine merek Cometech tipe QC-601A.

\section{Metode Penelitian Persiapan bahan}

Semua bahan ditimbang menggunakan neraca analitik dengan resin polipropilena sejumlah 196 gram dan masterbatch sejumlah 4 gram pada setiap campuran awal. Campuran awal tersebut dimasukkan ke dalam suatu wadah dan dikocok sampai sekiranya homogen selama 3 menit. Jumlah massa campuran bahan pembersih adalah 300 gram dengan massa resin recycled HDPE dan lempung kaolin sesuai Tabel 1.

\section{Ekstrusi campuran awal}

Ekstrusi campuran awal dilakukan setiap sebelum ekstrusi bahan pembersih. Ekstrusi dilakukan pada temperatur $190{ }^{\circ} \mathrm{C}$ dengan kecepatan screw 100 rpm. Setelah material keluar melalui die head, kompon polipropilena/ masterbatch yang diperoleh didinginkan melalui waterbath untuk kemudian dipotong-potong oleh pelletizer menjadi berbentuk pelet-pelet.

\section{Ekstrusi campuran bahan pembersih}

Setelah ekstrusi campuran awal, temperatur extruder dinaikkan menjadi $210{ }^{\circ} \mathrm{C}$ dengan kecepatan screw tetap pada $100 \mathrm{rpm}$. Campuran variasi bahan pembersih diumpankan ke hopper, dan setelah melalui waterbath, dipotong-potong dalam pelletizer.

\section{Preparasi pelat sampel}

Pelat sampel diperoleh dengan memberikan panas dan menekan pelet-pelet ekstrudat bahan pembersih, kompon polipropilena/masterbatch, dan bahan baku recycled HDPE menggunakan manual forming machine. Temperatur operasi untuk kompon polipropilena/masterbatch adalah $190^{\circ} \mathrm{C}$ dan material lainnya yang berbasis recycled $H D P E$ diproses pada temperatur $210^{\circ} \mathrm{C}$.

\section{Karakterisasi Warna}

Uji warna suatu benda dilakukan dengan beberapa metode, diantaranya adalah HunterLab, dan CIE $L^{*} a^{*} b$. Commission Internationale de L'éclairage (CIE) pada 1976 mengeluarkan metode CIE LAB color space (Choudhury, 2015). CIE LAB color space merupakan diagram warna tiga dimensi yang menunjukkan posisi suatu warna. Nilai positif $a^{*}$ menunjukkan koordinat warna merah yang berlawanan dengan nilai $a^{*}$ negatif yang menunjukkan koordinat warna hijau. Nilai positif $b^{*}$ menunjukkan koordinat warna kuning yang berlawanan dengan nilai $b^{*}$ negatif yang menunjukkan koordinat warna biru. Nilai $L$ menunjukkan koordinat lightness (kecerahan), semakin tinggi nilai $L$, semakin terang warnanya (Wee et al., 2006). Warna ekstrudat bahan pembersih diukur dalam bentuk pelat plastik dengan tebal $2 \mathrm{~mm}$. Pengukuran warna dilakukan dengan metode ASTM D2244-05 dengan CIE illuminant D 65-10. ASTM (2005) menyatakan perbedaan warna keseluruhan suatu benda dengan lainnya pada metode CIE $L^{*} a^{*} b$ disebut dengan $\Delta E^{*}{ }_{a b}$ yang didefinisikan sebagai Persamaan (1).

$\Delta E^{*}{ }_{a b}=\sqrt{\left(\Delta L^{*}\right)^{2}+\left(\Delta a^{*}\right)^{2}+\left(\Delta b^{*}\right.}$

dengan:

$\Delta L^{*}=$ perbedaan koordinat $L^{*}$ (lightness)

$\Delta a^{*}=$ perbedaan koordinat $a^{*}$ (merah-hijau)

$\Delta b^{*}=$ perbedaan koordinat $b^{*}$ (kuning-biru) 
Tabel 1. Variasi komposisi bahan pembersih.

\begin{tabular}{ccccc}
\hline Variasi bahan & \multicolumn{2}{c}{ Persentase massa (\%wt) } & \multicolumn{2}{c}{ Jumlah massa (gram) } \\
\cline { 2 - 5 } pembersih & Recycled HDPE & Lempung & Recycled HDPE & Lempung \\
\hline PM Variasi 1 & 100 & 0 & 300 & 0 \\
PM Variasi 2 & 97 & 3 & 291 & 9 \\
PM Variasi 3 & 94 & 6 & 282 & 18 \\
PM Variasi 4 & 91 & 9 & 273 & 27 \\
\hline
\end{tabular}

\section{Spektroskopi Infra-Merah}

Instrumen yang digunakan untuk menjelaskan serapan spektrum suatu senyawa disebut dengan spektrofotometer. Fourier transform infrared (FTIR) spectroscopy adalah suatu alat yang digunakan untuk memperoleh penyerapan, emisi, fotokonduktivitas, penghamburan gelombang infra-merah dari suatu padatan, cairan, atau gas. Alat uji gugus fungsi adalah ATR-FTIR spectroscopy Thermofisher Scientific Nicolet tipe iS20 dengan metode Indonesia Customs and Excise Laboratory Guide (ICEL) 1500.M01.

\section{HASIL DAN PEMBAHASAN}

Pencitraan digital warna sampel yang ditunjukkan oleh Gambar 1 dan ukuran koordinat warna ditunjukkan oleh Tabel 2. Hasil pengukuran warna digunakan untuk menghitung nilai perbedaan warna untuk masing-masing koordinat warna dan keseluruhan perbedaan warna $\left(\Delta E^{*}{ }_{a b}\right)$ dari jenis-jenis sampel terhadap bahan ekstrusi awal yang dibersihkan, yaitu PP/masterbatch $2 \%$ dan terhadap bahan baku purge material (PM), yaitu recycled HDPE. Persamaan 1 digunakan untuk menghitung $\Delta \mathrm{E}^{*}{ }_{\mathrm{ab}}$. terhadap $\mathrm{PP} /$ masterbatch dan dianalisis melalui diagram garis pada Gambar 2.

Perbedaan warna pada masing-masing koordinat menunjukkan kecenderungan arah warna. Nilai positif $\Delta L^{*}$ menunjukkan warna lebih terang, sedangkan negatif $\Delta L^{*}$ menunjukkan warna lebih gelap. Nilai positif $\Delta a^{*}$ menunjukkan warna lebih merah, sedangkan nilai negatif $\Delta a^{*}$ menunjukkan warna lebih hijau. Nilai positif $\Delta b^{*}$ menunjukkan warna lebih kuning, sedangkan nilai negatif $\Delta b^{*}$ menunjukkan warna lebih biru. Contoh perhitungan perbedaan keseluruhan bahan recycled HDPE warna terhadap ekstrudat $\mathrm{PP} /$ masterbatch $2 \%$ seperti terlihat di bawah ini:

$$
\begin{aligned}
& \Delta L^{*} \quad=L^{*}{ }_{\text {recycled } \mathrm{HDPE}}-L^{*}{ }_{P P / \text { masterbatch } 2 \%} \\
& =55,18-38,42=16,72
\end{aligned}
$$

$$
\begin{array}{rr}
\Delta a^{*} & =a^{*}{ }_{\text {recycled } \mathrm{HDPE}^{-}} a^{*}{ }_{P P / \text { masterbatch } 2 \%} \\
& =0,97-40,93=-39,96 \\
& =b^{*}{ }_{\text {recycled } \mathrm{HDPE}^{-}} b^{*}{ }_{P P / \text { masterbatch } 2 \%} \\
\Delta b^{*} \quad & 12,53-23,59=-11,06
\end{array}
$$

Angka yang dihasilkan pada persamaan (2), (3), dan (4) selanjutnya dimasukkan ke dalam persamaan (1).

$\Delta E^{*}{ }_{a b}=\sqrt{\left(\Delta L^{*}\right)^{2}+\left(\Delta a^{*}\right)^{2}+(\Delta b)^{2}}=$ $\sqrt{(16,72)^{2}+(-39,96)^{2}+(-11,06)^{2}}=44,72$

Perbedaan warna keseluruhan bahan baku recycled HDPE terhadap warna $\mathrm{PP} /$ masterbatch $2 \%$ diperoleh sebesar 44,72. Hal ini menunjukkan bahwa recycled HDPE yang digunakan memiliki warna yang jauh berbeda dari bahan yang ingin dibersihkan, yaitu $\mathrm{PP} /$ masterbatch $2 \%$. Warna primer dari $\mathrm{PP} /$ masterbatch adalah merah dengan nilai koordinat $a^{*}$ sebesar 40,93, sedangkan warna bahan baku bahan pembersih recycled HDPE adalah kuning pucat dengan rata-rata koordinat $L^{*}$ sebesar 55,18 dan koordinat $b^{*}$ sebesar 12,53 . Bahan pembersih yang baik adalah yang mengeluarkan sisa material sebelumnya dari dalam barel. Salah satu kondisi yang dapat menunjukkan barel sudah bersih dari material yang sebelumnya adalah warna material sebelumnya sudah menghilang.

Terlihat dari Gambar 2 bahwa perbedaan koordinat warna primer $\mathrm{PP} /$ masterbatch $2 \%$ (merah), yaitu $\Delta a^{*}$ pada variasi bahan pembersih paling besar ada pada variasi 4 sebesar 37,37 , diikuti oleh variasi 3 sebesar 37,05 , variasi 2 sebesar 36,19, dan yang paling kecil adalah variasi 1 sebesar 35,61. Hal ini menunjukkan bahwa warna ekstrudat semakin tidak merah atau semakin hijau seiring penambahan lempung kaolin pada bahan pembersih berbasis recycled HDPE.

Perbedaan warna keseluruhan $\left(\Delta E_{a b}^{*}\right)$ variasi bahan pembersih terhadap $\mathrm{PP} /$ masterbatch $2 \%$ dari yang paling besar secara berurutan adalah variasi 4 sebesar 40,38, variasi 3 sebesar 40,21, variasi 2 sebesar 39,55 , dan variasi 1 sebesar 
Tabel 2. Hasil pengukuran warna.

\begin{tabular}{clrrr}
\hline No. & \multicolumn{1}{c}{ Jenis sampel } & \multicolumn{1}{c}{$L^{*}$} & \multicolumn{1}{l}{$a^{*}$} & \multicolumn{1}{l}{${ }^{*}$} \\
\hline 1. & PP/masterbatch 2\% & 38,42 & 40,93 & 23,59 \\
2. & Bahan baku recycled HDPE & 55,18 & 0,97 & 12,53 \\
3. & PM variasi 1: recycled HDPE/lempung 0\% & 50,08 & 5,32 & 11,79 \\
4. & PM variasi 2: recycled HDPE/lempung 3\% & 50,52 & 4,74 & 13,19 \\
5. & PM variasi 3: recycled HDPE/lempung 6\% & 49,42 & 3,88 & 12,48 \\
6. & PM variasi 4: recycled HDPE/lempung 9\% & 48,78 & 3,56 & 12,35 \\
\hline
\end{tabular}

39,28. Hal ini menunjukkan warna dari PP/ masterbatch semakin menghilang dalam ekstrudat bahan pembersih seiring penambahan komposisi lempung kaolin pada campuran bahan pembersih recycled HDPE yang digunakan. Berdasarkan perbedaan warna tersebut, dapat dikatakan nilai perbedaan warna terjadi karena hilangnya warna $\mathrm{PP} /$ masterbatch $2 \%$ yang memiliki warna primer merah pada penelitian ini. Berdasarkan hal-hal di atas, dapat disimpulkan bahwa bahan pembersih yang paling baik adalah bahan pembersih variasi 4, yaitu campuran recycled HDPE/empung 9\%.
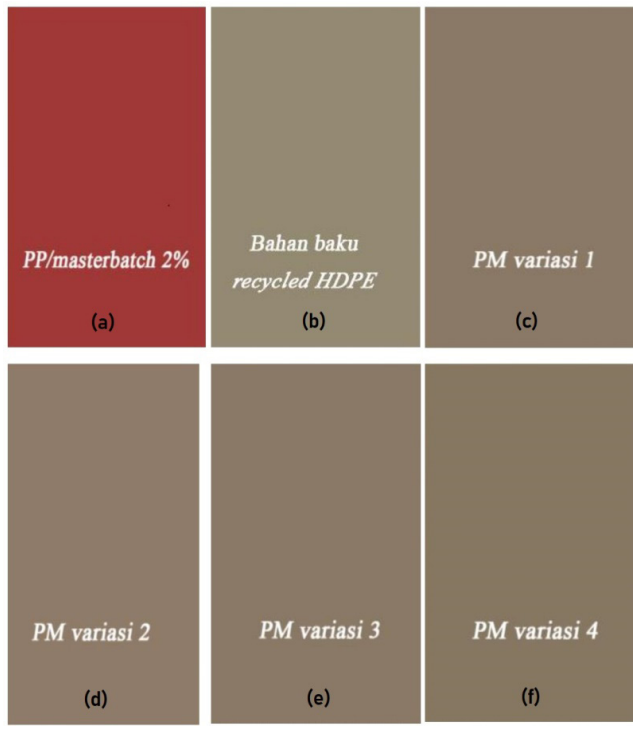

Gambar 1.Pencitraan digital warna sampel bahan baku recycled HDPE (a), PP/masterbatch 2\% (b), PM variasi 1 (c), PM variasi 2 (d), PM variasi 3 (e), dan PM variasi 4 (f).

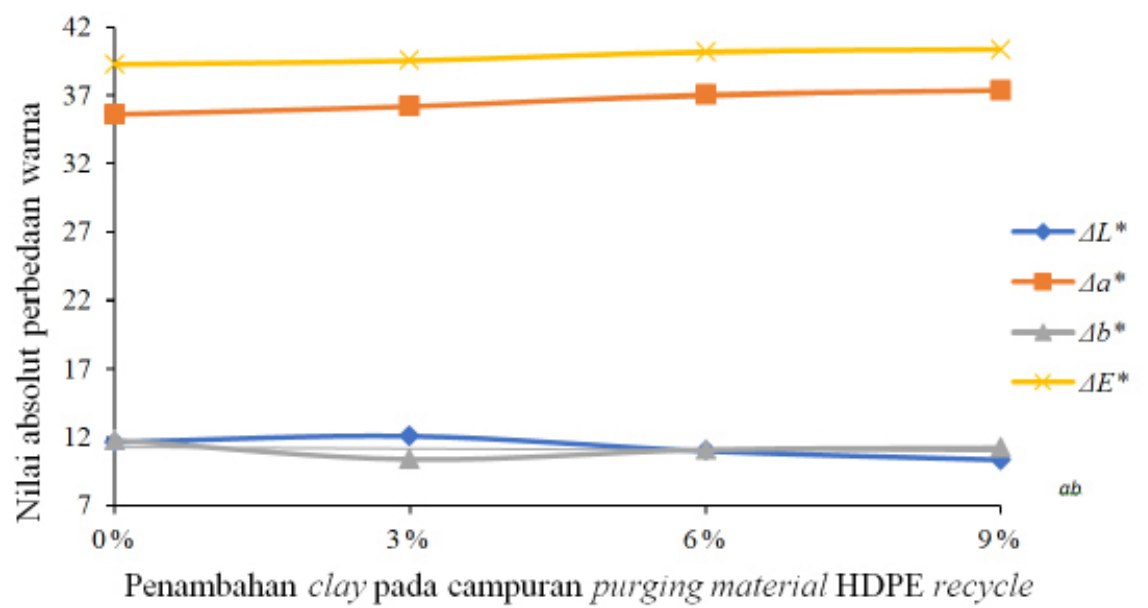

Gambar 2. Perbedaan warna dengan PP/masterbatch 2\% terhadap penambahan lempung pada bahan pembersih recycled HDPE. 
$\Delta E^{*}{ }_{a b}$ dari variasi penambahan lempung pada campuran bahan pembersih recycled HDPE menghasilkan warna ekstrudat yang makin berbeda dari penambahan 3\% sampai 9\% lempung terhadap bahan baku recycled HDPE yang digunakan. Hal ini menunjukkan bahwa warna ekstrudat bahan pembersih tidak hanya dipengaruhi kontaminasi $\mathrm{PP} /$ masterbatch $2 \%$, namun juga sudah terpengaruh karena penambahan lempung.

\section{Hasil Uji Gugus Fungsi}

Spektrum hasil uji gugus fungsi ditunjukkan oleh Gambar 3 dan temuan gugus fungsi diberikan pada Tabel 3.

Terdapat serapan infra-merah pada bilangan gelombang $1746,70 \mathrm{~cm}^{-1}$ yang mengindikasikan gugus $\mathrm{C}=\mathrm{O}$ dan pada $1255,99 \mathrm{~cm}^{-1}$ yang mengindikasikan gugus $\mathrm{C}-\mathrm{O}$ pada ekstrudat $\mathrm{PP} /$ masterbatch $2 \%$. Senyawa ester tersebut kemungkinan berasal dari masterbatch yang digunakan. Hal ini didukung data bahwa keberadaan ikatan $\mathrm{C}=\mathrm{O}$ dengan bilangan gelombang 1750-1730 $\mathrm{cm}^{-1}$ menunjukkan golongan ester sedangkan ikatan $\mathrm{C}-\mathrm{O}$ dengan bilangan gelombang $1300-1000 \mathrm{~cm}^{-1}$ menunjukkan golongan alkohol, eter, ester, asam karboksilat, serta anhidrida (Pavia et al., 2008). Keberadaan gugus $\mathrm{OH}$ pada puncak bilangan gelombang 3695 $\mathrm{cm}^{-1}$ dan $3359,25 \mathrm{~cm}^{-1}$ dengan intensitas rendah menunjukkan keberadaan sedikit kandungan air dalam sampel recycled HDPE.
Pada PM variasi 1, menunjukkan pergeseran gugus fungsi dan terdapat gugus karboksilat, yaitu $\mathrm{O}-\mathrm{H}, \mathrm{C}-\mathrm{O}$, dan $\mathrm{C}=\mathrm{O}$ pada bilangan gelombang $3380,57 \mathrm{~cm}^{-1}, 1375,12 \mathrm{~cm}^{-1}$, dan $1643,68 \mathrm{~cm}^{-1}$. Hal ini terjadi karena adanya bahan pembersih yang mengandung lempung kaolin dan telah mengalami kontak dengan air selama proses pendinginan ekstrudat dalam waterbath. Gugus $\mathrm{C}-\mathrm{C}$ pada bilangan gelombang $1166,31 \mathrm{~cm}^{-1}$ menunjukkan masih ada rantai cabang alkil yang kemungkinan berasal dari sisa polipropilena yang dibersihkan sehingga dapat disimpulkan masih terdapat kontaminasi $\mathrm{PP} /$ masterbatch $2 \%$ pada $\mathrm{PM}$ variasi 1.

Pada PM variasi 2, masih ditemukan puncak serapan intensitas rendah untuk gugus $\mathrm{O}-\mathrm{H}$, $\mathrm{C}=\mathrm{O}$, dan $\mathrm{C}-\mathrm{H}$ yang menunjukkan bahwa sampel $\mathrm{PM}$ variasi 2 juga mengalami pergeseran gugus fungsi, namun tidak sebesar yang terjadi pada PM variasi 1 . Keberadaan lempung kaolin pada PM variasi 2 ditunjukkan oleh keberadaan gugus $\mathrm{Si}-\mathrm{O}$ dan $\mathrm{Al}_{2} \mathrm{OH}$. Gugus $\mathrm{O}-\mathrm{H}$ berasal dari air yang menyerap di dalam lempung kaolin pada proses pendinginan di waterbath. Gugus rantai cabang $\mathrm{C}-\mathrm{C}$ tidak ditemukan dalam hasil uji $\mathrm{PM}$ variasi 2 menandakan bahwa polipropilena dalam PP/ masterbatch $2 \%$ tidak mengkontaminasi material akhir purging dengan PM variasi 2.

Pada hasil uji esktrudat gugus fungsi PM variasi 3, tidak ditemukan gugus $\mathrm{C}=\mathrm{O}$, namun masih ada gugus $\mathrm{C}-\mathrm{O}$. Hal ini menunjukkan

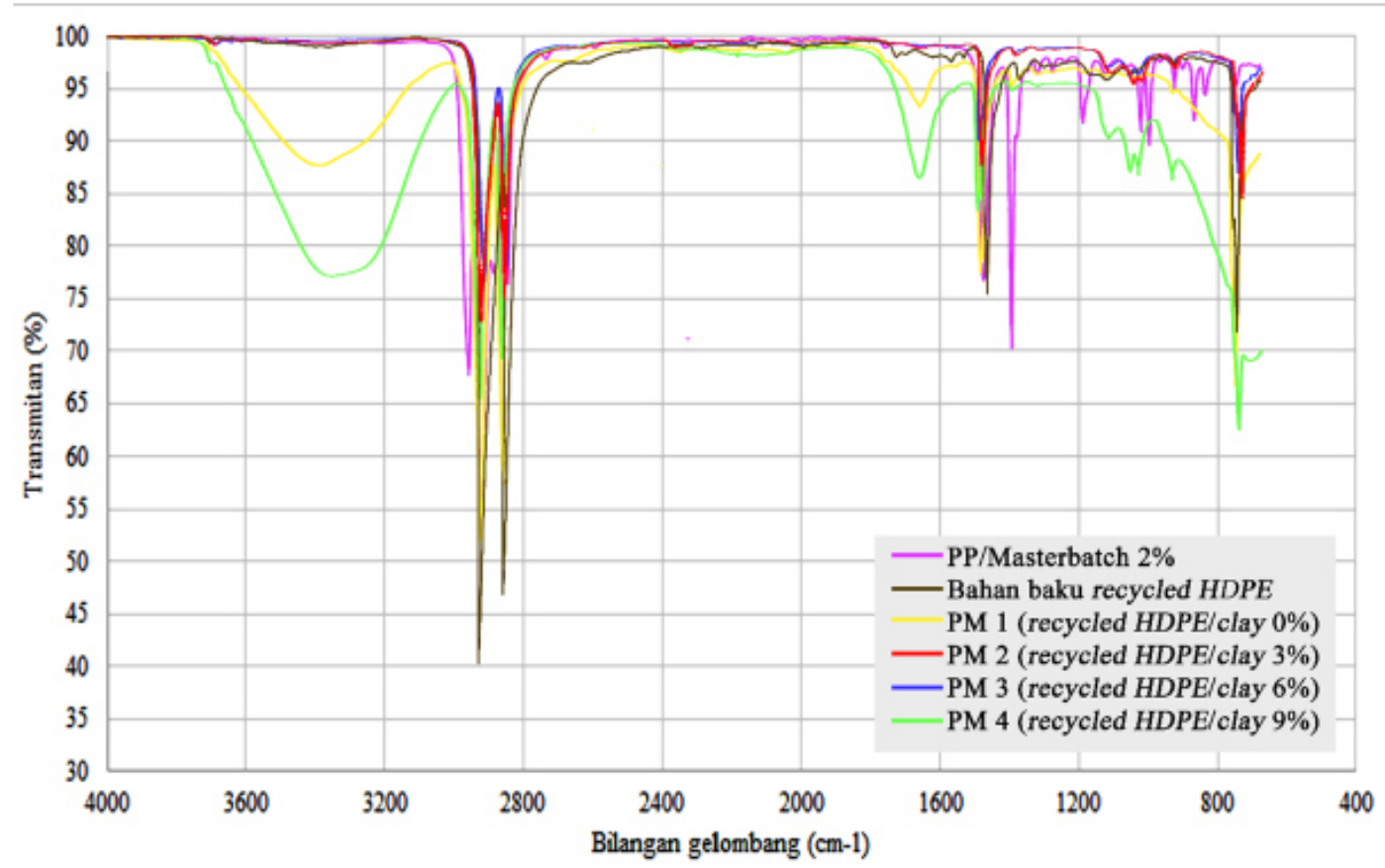

Gambar 3. Spektrum infra-merah. 
Tabel 3. Puncak serapan infra-merah hasil uji gugus fungsi.

\begin{tabular}{|c|c|c|c|c|c|c|}
\hline \multirow[b]{2}{*}{ Gugus fungsi } & \multicolumn{6}{|c|}{ Puncak serapan $\left(\mathrm{cm}^{-1}\right)$} \\
\hline & $\begin{array}{c}\mathrm{PP} / \mathrm{MB} \\
2 \%\end{array}$ & $\begin{array}{l}\text { RW HDPE } \\
r e .\end{array}$ & $\begin{array}{c}\text { PM } \\
\text { variasi } 1\end{array}$ & $\begin{array}{c}\text { PM } \\
\text { variasi } 2\end{array}$ & $\begin{array}{c}\text { PM } \\
\text { variasi } 3\end{array}$ & $\begin{array}{c}\text { PM } \\
\text { variasi } 4\end{array}$ \\
\hline $\mathrm{O}-\mathrm{H}$ stretch & - & $\begin{array}{l}3695,02 \\
3359,25\end{array}$ & 3380,57 & 3356,93 & 3618,80 & 3344,12 \\
\hline $\mathrm{C}-\mathrm{H}$ stretch asimetris & $\begin{array}{l}2950,31 \\
2917,00\end{array}$ & 2915,10 & 2914,79 & 2914,42 & 2913,70 & 2914,43 \\
\hline $\mathrm{C}-\mathrm{H}$ stretch simetris & $\begin{array}{l}2868,75 \\
2838,61\end{array}$ & 2847,57 & 2847,89 & 2847,71 & 2847,07 & 2847,65 \\
\hline $\mathrm{C}=\mathrm{O}$ stretch asimetris & 1746,70 & - & 1643,68 & 1647,48 & - & 1637,66 \\
\hline $\mathrm{C}-\mathrm{H}$ bend asimetris & 1455,92 & 1461,87 & 1461,87 & 1469,69 & 1469,92 & 1469,89 \\
\hline $\mathrm{C}-\mathrm{H}$ bend simetris & 1375,73 & - & - & - & - & - \\
\hline $\mathrm{C}-\mathrm{O}$ stretch & $\begin{array}{c}1255,59 \\
\text { (ester) }\end{array}$ & 1374,02 & 1375,12 & 1374,60 & 1375,32 & 1374,62 \\
\hline $\mathrm{C}-\mathrm{C}$ stretch asimetris & 1166,62 & - & 1166,31 & - & - & - \\
\hline $\mathrm{Si}-\mathrm{O}$ stretch & - & - & - & $\begin{array}{l}1096,98 \\
1030,89 \\
1008,48\end{array}$ & $\begin{array}{l}1096,60 \\
1031,47 \\
1008,19\end{array}$ & $\begin{array}{c}1094,431031,25 \\
1008,03\end{array}$ \\
\hline $\mathrm{Al}_{2} \mathrm{OH}$ bend & - & - & - & 910,57 & 910,91 & 910,32 \\
\hline $\mathrm{C}-\mathrm{H}$ rock asimetris & $\begin{array}{l}997,50 \\
972,94 \\
898,96\end{array}$ & - & - & - & - & - \\
\hline $\mathrm{C}-\mathrm{H}$ rock & $\begin{array}{l}840,97 \\
808,56\end{array}$ & $\begin{array}{l}728,78 \\
718,42\end{array}$ & 717,52 & 717,21 & 717,56 & 717,15 \\
\hline
\end{tabular}

bahwa PM variasi 3 tidak menghasilkan senyawa asam karboksilat. Gugus karbonil kemungkinan berasal dari end group rantai polimer recycled HDPE. Lempung kaolin dideteksi dengan adanya puncak serapan gugus $\mathrm{Si}-\mathrm{O}$ dan $\mathrm{Al}_{2} \mathrm{OH}$. Nilai pada bilangan gelombang juga dapat menunjukkan intensitas serapan pada masing-masing variasi. Intensitas serapan $\mathrm{Al}_{2} \mathrm{OH}$ pada bilangan gelombang $910,57 \mathrm{~cm}^{-1}$ variasi 2 dan $910,91 \mathrm{~cm}^{-1}$ pada variasi 3 menunjukkan gugus fungsi $\mathrm{Al}_{2} \mathrm{OH}$ pada $\mathrm{PM}$ variasi 3 tersebut lebih besar dibandingkan PM variasi 2. Hal ini karena PM variasi 3 memiliki massa lempung kaolin yang lebih besar. Pada hasil uji PM variasi 3 pun tidak ditemukan gugus rantai cabang $\mathrm{C}-\mathrm{C}$.

Pada hasil uji esktrudat gugus fungsi PM variasi 4 , gugus $\mathrm{O}-\mathrm{H}$ pada bilangan gelombang $3344,12 \mathrm{~cm}^{-1}$ memiliki intensitas absorbansi yang besar dibanding hasil uji gugus fungsi lainnya. Hal ini karena lempung kaolin pada penambahan 9\% menyerap air lebih dan membuat pelet-pelet basah. Intensitas absorbansi gugus $\mathrm{C}=\mathrm{O}$ juga lebih besar yang menunjukkan sampel uji teroksidasi menghasilkan senyawa asam karboksilat.

Intensitas absorbansi lempung kaolin lebih besar yang menunjukkan bahwa massa lempung kaolin pada sampel PM variasi 4 lebih besar daripada sampel PM variasi 3. Gugus $\mathrm{C}-\mathrm{C}$ rantai samping juga tidak ditemukan pada polipropilena dalam $\mathrm{PP} /$ masterbatch $2 \%$.

Berdasarkan semua hasil uji bahan pembersih berbasis recycled HDPE pada variasi 1 sampai 4, ditemukan bahwa sampel-sampel telah teroksidasi. Hasil uji yang paling baik ditemukan pada PM variasi 3, yaitu bahan pembersih recycled HDPE/ lempung 6\%. Hasil uji PM variasi 3 memiliki keunggulan karena tidak ditemukan kontaminasi $\mathrm{PP} /$ masterbatch $2 \%$ yang dibersihkan dan relatif tidak teroksidasi. Jika bahan pembersih memiliki senyawa alkohol dan asam karboksilat maka akan menambah resiko korosi pada bagian barel extruder.

Hasil pengujian-pengujian di atas dapat disimpulkan bahwa sampai penambahan 9\% lempung kaolin pada bahan pembersih berbasis recycled HDPE masih terjadi peningkatan daya bersih ditinjau dari warna ekstrudat purging namun masih terdapat gugus fungsi pengotor, 
tetapi tidak ditemukan di variasi penambahan $6 \%$ lempung kaolin. Hal ini mungkin terjadi karena faktor viskositas lelehan bahan pembersih dalam barel. Penambahan lempung kaolin menyebabkan viskositas lelehan HDPE lebih kecil sehingga ketika digunakan sebagai bahan pembersih mampu meraih sudut-sudut dalam barel, namun jika viskositasnya terlalu rendah maka tidak mampu mendorong material residu yang ingin dibersihkan. Oleh sebab itu, kemungkinan pada variasi bahan pembersih recycled HDPE/lempung $9 \%$ terjadi pembersihan yang lebih intens pada bagian dalam barel, namun kurang mendorong residu $\mathrm{PP} /$ masterbatch $2 \%$ yang menyebabkan hasil warna ekstrudat lebih bersih namun masih terdapat pengotor yang tidak terlihat mata.

Berdasarkan penelitian ini, bahan pembersih berbasis recycled HDPE yang disarankan untuk membersihkan campuran polipropilena pada extruder skala lab adalah PM variasi 3, yaitu recycled HDPE/lempung 6\%. Ekstrudat hasil PM variasi 3 ini menunjukkan warna yang cukup bersih dan tidak terdapat gugus pengotor. Bahan pembersih yang berada dalam barel setelah purging juga akan mudah dikeluarkan dengan memasukkan material yang akan diekstrusi selanjutnya. Pada variasi ini, serbuk lempung kaolin yang masih tertinggal pada hopper dan zona feeding juga lebih mudah dibersihkan dibanding jumlah serbuk lempung kaolin pada campuran PM variasi 4.

\section{KESIMPULAN}

Penambahan lempung kaolin sebagai campuran bahan pembersih berbasis recycled HDPE untuk ekstrusi campuran $\mathrm{PP} /$ masterbatch $2 \%$ menghasilkan ekstrudat berwarna terkontaminasi $\mathrm{PP} /$ masterbatch $2 \%$ yang semakin menghilang. Penambahan lempung kaolin sebagai campuran bahan pembersih berbasis recycled HDPE untuk ekstrusi $\mathrm{PP} /$ masterbatch $2 \%$ menghasilkan ekstrudat yang masih mengandung gugus cabang $\mathrm{C}-\mathrm{C}$ polipropilena pada penambahan $0 \%$ massa lempung kaolin, mengandung gugus fungsi senyawa asam karboksilat pada penambahan $0 \%, 3 \%$, dan $9 \%$ massa lempung kaolin, dan mengandung gugus fungsi alkohol pada penambahan 6\% massa lempung kaolin. Oleh sebab itu, campuran recycled HDPE/lempung kaolin $6 \%$ adalah bahan pembersih yang disarankan untuk ekstrusi produk dengan kandungan masterbatch lebih rendah dibandingkan variasi lainnya karena diperoleh kontaminasi warna dan kandungan gugus fungsi residu yang rendah pada ekstrudatnya. Perlu dilakukan penelitian lanjutan tentang pengaruh penggunaan bahan pembersih terhadap waktu pencucian barel, analisis gugus fungsi ekstrudat dilaksanakan sebelum sampel uji masuk ke waterbath untuk mengurangi penyerapan air dalam bahan pembersih, serta dilakukan aplikasi bahan pembersih pada proses ekstrusi lainnya.

\section{UCAPAN TERIMA KASIH}

Terima kasih diucapkan kepada Politeknik STMI Jakarta, PT S-IK, Cikarang, Laboratorium Bea Cukai, Jakarta atas sarana dan prasarana yang diberikan serta pihak-pihak yang terlibat penelitian ini.

\section{DAFTAR PUSTAKA}

Agassant, J. F., Avenas, P., Carreau, P. J., Vergnes, B., \& Vincent, M. (2017). Polymer processing: Principles and modelling. Munich, Germany: Carl Hanser Verlag. https://doi. org $/ 10.3139 / 9781569906064$

ASTM. (2005). ASTM D2244-05, Standard practice for calculation of color tolerances and color differences from instrumentally measured color coordinates. West Conchohocken, US: ASTM International. https://doi.org/10.1520/D2244-05

Bajpai, P. (2016). Pulp and paper industry: Chemicals. Amsterdam, Netherlands: Elsevier. https://doi. org/10.1016/C2014-0-02795-5

Choudhury, A. K. R. (2015). Principles of colour and appearance measurement: Volume 2: Visual measurement of colour, colour comparison and management. Cambridge, England: Woodhead Publishing. https://doi.org/10.1016/C2014-001832-1

Chukwubuike, O. (2015). Purging mixture for extruder (Tesis). Arcada University, Finland.

Giles, H. F., Wagner, J. R. \& Mount, E. M. (2004). Extrusion: The definitive processing guide and handbook. New York, USA: William Andrew.

Gill, Y. Q., Jin, J., \& Song, M. (2015). Melt flow behavior of high density polyethylene nanocomposites with 1D, 2D and 3D nanofillers. Nanocomposites, 1(3), 160-169. https://doi.org/10.1179/20550332 $15 \mathrm{Y} .0000000012$

Lewis, J. R. (2007). Hawley's condensed chemical dictionary (15th ed.). New York, USA: John Wiley \& Sons.

Lin, J.H., Pan, Y.J., Liu, C.F., Huang, C.L., Hsieh, C.T., Chen, C.K., Lin, Z.L., \& Lou, C.W. (2015). Preparation and compatibility evaluation of polypropylene/high density polyethylene 
polyblends. Materials, 8(12), 8850-8859. https:// doi.org/10.3390/ma8125496

Pavia, D. L., Lampman, G. M., Kriz, G. S., \& Vyvyan, J. A. (2008). Introduction to Spectroscopy (4th ed.). Boston, USA: Cengage Learning.

Pukánszky, B. (2001). Mineral-filled polymers. In Buschow, K. H. J., Cahn, R. W., Flemings, M. C., Ilschner, B., Kramer, E. J., Mahajan, S., \& Veyssière, P. (2nd eds.)., Encyclopedia of materials: Science and technology (pp. 5680-
5683). London, UK: Pergamon Press. https://doi. org/10.1016/B0-08-043152-6/00989-X

Tolinski, M. (2015). Additives for poliolefins: Getting the most out of polypropylene, polyethylene and TPO (2nd ed.). Oxford, UK: William Andrew.

Wee, A. G., Lindsey, D. T., Kuo, S., \& Johnston, W. M. (2006). Color accuracy of commercial digital cameras for use in dentistry. Dental Materials, 22(6), 553-559. https://doi.org/10.1016/j. dental.2005.05.011 
